\title{
Mentoring in cardiology: A New Teaching Tool in a Rapidly Transforming World
}

\author{
Evandro Tinoco Mesquita, ${ }^{1}$ Amanda Cunha Soares, ${ }^{1,2}{ }^{\circledR}$ Ricardo Cardoso de Matos ${ }^{1}$ \\ Universidade Federal Fluminense - Hospital Universitário Antonio Pedro, ${ }^{1}$ Niterói, RJ - Brazil \\ Unigranrio, ${ }^{2}$ Duque de Caxias, $R J$ - Brazil
}

\section{Abstract}

This is an article aimed at showing the mentoring role in a fast-changing society, particularly during and after the COVID-19 pandemic. The intense flow of information feelings and new knowledge makes it necessary for medical education to be updated to keep up with social and professional dynamics, according to health requirements and new knowledge demands.

The mentoring program is a development process in which the mentor promotes the mentee professional and personal growth, by the exchange of visions and experiences. It allows an increase in the repertoire of solutions, particularly important in such an unstable context imposed by the pandemic. The mentor and mentee are challenged to move from a traditional to a virtual environment, characterized by physical distancing, development of digital medicine and distance learning.

\section{Article Motivation}

This article was motivated by the experience with the project implemented by the Cardiology Society of Rio de Janeiro (SOCERJ). The project, launched at the 2018 SOCERJ Congress, aims to promote experienced medical professionals and teachers as mentors of medical students and young doctors. In addition, the COVID-19 pandemic was another important motivating factor for this study, since at this crucial moment for healthcare in Brazil and worldwide, the development of leadership and the use of digital technologies make a difference in this scenario of uncertainties.

\section{Keywords}

Mentors; Mentoring; Cardiology.

\section{Historical context / Historical background}

The concept of mentoring originated from the Homer's famous "The Odyssey". In the epic poem, Odysseus, the king of Ithaca, entrusted Mentor with the great challenge of preparing his son, Telemachus, to replace his father after he leaves for the Trojan War. Telemachus was not only under the tutelage of the Mentor, but also under his supervision and guidance to become prepared for future responsibilities. In 1750, the word "mentor" was incorporated into the English and French dictionaries, with the words: advisor, friend, tutor, teacher, and wise man as synonymous. ${ }^{1}$

\section{"Mentoring" in Brazilian medical schools}

In Brazil, the mentoring process is known as "mentoria". Although the latter has been more restricted and limited to technical knowledge, both processes fall within the movement of changing medical teaching. Changes are being made to the curriculum guidelines and are being established with the intention of forming mentoring and, to a lesser extent, mentoring programs (2).

In order to provide a more active training, some medical schools in Brazil have adopted methods that help in this process, which, although not based on the mentoring format, makes the teaching-learning process more dynamic. The Marília Medical School one of the first in the active methodology of problem-based teaching (PBL) in Brazil, Problem Based Learning program in the medical course in 1997. ${ }^{5}$ The Rio Grande do Norte Medical School implemented a mentoring program in 2015, with integrative activities between students and teachers of the university. The objective of the program was to promote the development of mental, professional and academic health of students. ${ }^{3}$ The São Paulo State University has incorporated mentoring into the support and development program format, where students have

Mailing Address: Amanda Soares

Rua Professor José de Souza Herdy, 1160. Postal Code: 25071-070, Duque de Caxias,

RJ - Brazil.

E-mail: amandamalu.lucas@gmail.com 
the opportunity to meet monthly with experienced doctors who encourage them to evaluate the profession and support them during their undergraduate studies. ${ }^{4}$

\section{Importance of mentoring}

Medical academics and young doctors have faced increasing challenges in terms of the volume of information, concepts, professional opportunities and the speed of technology development. In this context, mentoring becomes a valuable tool for career development and preservation of physical and mental health. ${ }^{6}$ According to Agarwal et al., ${ }^{7}$ a good mentor makes you not only a more qualified professional, but a better human being. In addition, it has been demonstrated that mentoring has allowed an increase in career satisfaction and stimulated the presence of more professionals involved in mentoring projects. ${ }^{8}$

In recent years, medical societies, in Brazil and abroad, have created mentoring programs to develop technical and personal skills, and consequently better academic performance. Young students are in contact with senior professionals, who, during discussions of cases and technical medical procedures, allow students to acquire important skills for the profession.

The new national curriculum guidelines of the undergraduate medical course point out that, among doctor skills and competences, there are four pillars on which the mentoring process can have great impact - 1) continuing education, 2) communication, 3) management and 4) medical leadership, all present in the mentor-mentee binomial process. ${ }^{9}$ Another concern of mentoring programs is the increasing number of "burnout syndrome" cases among medical students. This condition has been recently made official by the World Health Organization (WHO) as a chronic syndrome and will be included in the new International Classification of Diseases (ICD-11). The number of "Burnout" cases have increased among physicians, secondary to technological changes in the work environment, increased bureaucracy, and imbalance between personal and professional life, leading to an increase in chemical abuse, depression, and suicide rates. ${ }^{10}$

\section{The mentoring}

Regarding the current physician training, it is known that there is a great priority for the development of technical skills to the detriment of other formations also important for the apprentice, including knowledge of cognitive skills and postures in professional training. In this sense, the mentor plays a fundamental role in the process of mentoring by developing resourcefulness skills in the professional environment and promoting psycho-emotional control. ${ }^{10}$

\section{The mentor}

There are no strict rules to finding a mentor. Often the mentor-apprentice relationship begins as a boss and subordinate or as a teacher-student connection, which evolves over time into a mentoring relationship. It may be difficult to choose the ideal mentor due to the dynamic nature of the mentor and apprentice relationship, which depends on personality, aptitude, and attitude of both parties. ${ }^{7}$

\section{Types of mentor}

Currently, some authors believe that throughout a person's life there must be more than one mentor, or the same one may have more than one characteristic, as exemplified in Table 1. Such a situation is based on rapid changes in technology, organizational structure, and global health market dynamics. ${ }^{7}$ According to Janasz et al., ${ }^{11}$ as more information is available, it is difficult for an individual mentor to process all the knowledge required by the mentee, making it necessary to form and maintain a network.

Given this scenario, we can infer that it would be of great importance that medical schools and medical societies, aiming at a more holistic development of students and professionals, analyze the possibility of progressively offering greater means of training for the mentoring process. In addition to providing a more complete development of students and professionals, the process also allow measuring the results of mentoring process in the development of the medical professional.

\section{Mentoring in practice}

Medicine practice requires excellence in performance, satisfaction, quality of care and good safety practices for the patient. It may become deficient in light of the increasing complexity of the training of new doctors, imposed by the health environment changes.12 Thus, to fill the training gaps, the mentor plays a determinant role in an encompassing professional training12 (Table 2). 
Table 1 - The main types of mentors

\begin{tabular}{|c|c|c|}
\hline Level & Types of Mentors & Mentee's benefits \\
\hline I. & Educator & $\begin{array}{l}\text { Promotes the advancement of apprenticeship education, including medical knowledge, technical } \\
\text { proficiency, and procedural and digital skills. }\end{array}$ \\
\hline II. & Defiant & Encourages the mentee to contribute to the dedicated work and achieve high levels of excellence. \\
\hline III. & Moderate & $\begin{array}{l}\text { Makes questions that encourage the mentee examine his/her actions to generate continuous } \\
\text { learning and change of values. }\end{array}$ \\
\hline IV. & Planner & $\begin{array}{l}\text { Stimulates career planning and time management, considering the mentee's skills and the } \\
\text { mentor's experience. }\end{array}$ \\
\hline $\mathrm{V}$. & Connecter & $\begin{array}{l}\text { The mentor uses his influence and his network of contacts for the mentee to participate in projects } \\
\text { or enter the labor-market. }\end{array}$ \\
\hline VI. & Hybrid model & $\begin{array}{l}\text { Creates a model that combines the five profiles mentioned, throughout the development of the } \\
\text { mentoring process. }\end{array}$ \\
\hline
\end{tabular}

\section{Reverse mentoring and intergenerational aspects}

The medical work environment goes through a process of transformation never seen before, having in the increase of life expectancy an important pillar for the changes. This transition can be observed in the work environment, where 80-90-year-old professionals share space with younger generations, which highlights challenges of coexistence, adjustments, disruption, and respect to the characteristics of each time. ${ }^{13}$

In view of the traits of each generation, technological advances have striking importance among them and founded the idea of the "Generation Theory", represented by Figure 1. This theory shows that individuals exhibit similar behaviors as a function of the period in which they were born. ${ }^{13}$

\section{Definition of generations}

Traditionals (T): This is the generation of individuals born between 1925 and $1945 .^{13}$

Baby boomers (BB): People over 50 years old. They value a steady and stable job, taking into account the experience. ${ }^{13}$

Generation X: in professional life, this generation values positions, salaries, and functions. They remain long periods in the same company. ${ }^{13-15}$

Generation Y: in a short time of life, this generation witnessed the greatest advances in technology and electronic communication. It does not value the hierarchy so much and believes that working together offers great results. ${ }^{14,15}$

Generation Z: in the Internet era, they are known as "digital natives" with high levels of creativity, expressiveness, and individuality. Connected to mobile devices and other technological features, they are "native speakers" of digital language. ${ }^{16}$

Given all these diversities, the intergenerational aspects must be considered, so that the work environment becomes productive and harmonious. In this regard, a new concept called "Reverse Mentoring" has been created, in which the mentee is not the only one to learn and benefit from this relationship, since the new generations are connected, technological, creative and are open to the logic of the health transition observed over the last few years. ${ }^{17}$

In this process, the relationships established in the mentoring process can create a favorable environment for the mentor-mentee mutual growth. For the mentor, it can be a challenging and rewarding experience, that offers new perspectives, ideas, feedback in professional life, chance to develop in areas such as information technology, and mainly, opportunity for self-assessment on their technical and personal conduct in face of diverse situations. Building a synergistic relationship generates an environment of respect and friendship, making the two-way flow of learning and growth for both parties. ${ }^{17}$ 
Table 2 - Mentor's duties

\begin{tabular}{|c|c|c|}
\hline AREAS & DUTIES & DESCRIPTION \\
\hline \multirow{4}{*}{ Professional } & Support & $\begin{array}{c}\text { The mentor helps the mentee to obtain opportunities in the area of } \\
\text { operation. }\end{array}$ \\
\hline & Development & $\begin{array}{l}\text { The mentor creates opportunity for the mentee to demonstrate } \\
\text { competence and improve their performance. }\end{array}$ \\
\hline & Coaching & $\begin{array}{l}\text { The mentor teaches the mentee through sharing ideas and feedback, } \\
\text { suggests work strategies and tactics, and guides on career aspects. }\end{array}$ \\
\hline & Challenges & $\begin{array}{l}\text { The mentor supports the development of specific mentoring skills by } \\
\text { providing challenges and jobs that encourage learning, such as digital } \\
\text { mentoring and entrepreneurship. }\end{array}$ \\
\hline \multirow{4}{*}{ Personal } & Role modeling & $\begin{array}{l}\text { The mentor serves as an example, admiration and respect for the mentee. } \\
\text { It helps mentors to manage groups and tensions in the work environment } \\
\text { and family. }\end{array}$ \\
\hline & Acceptance and confirmation & $\begin{array}{l}\text { The mentor provides support and encouragement to the mentee. It makes } \\
\text { it possible to experiment with new behaviors. }\end{array}$ \\
\hline & Counselling & $\begin{array}{l}\text { The mentor listens to the mentee and supports him on personal concerns, } \\
\text { anxieties and fears that can affect his performance. }\end{array}$ \\
\hline & Friendship & $\begin{array}{l}\text { The mentor enables social interaction inside and outside the organization, } \\
\text { resulting in the exchange of information in a more informal environment and } \\
\text { with a mutual understanding. It promotes the sharing of personal experiences. }\end{array}$ \\
\hline
\end{tabular}

Figure 1 - Generation Theory

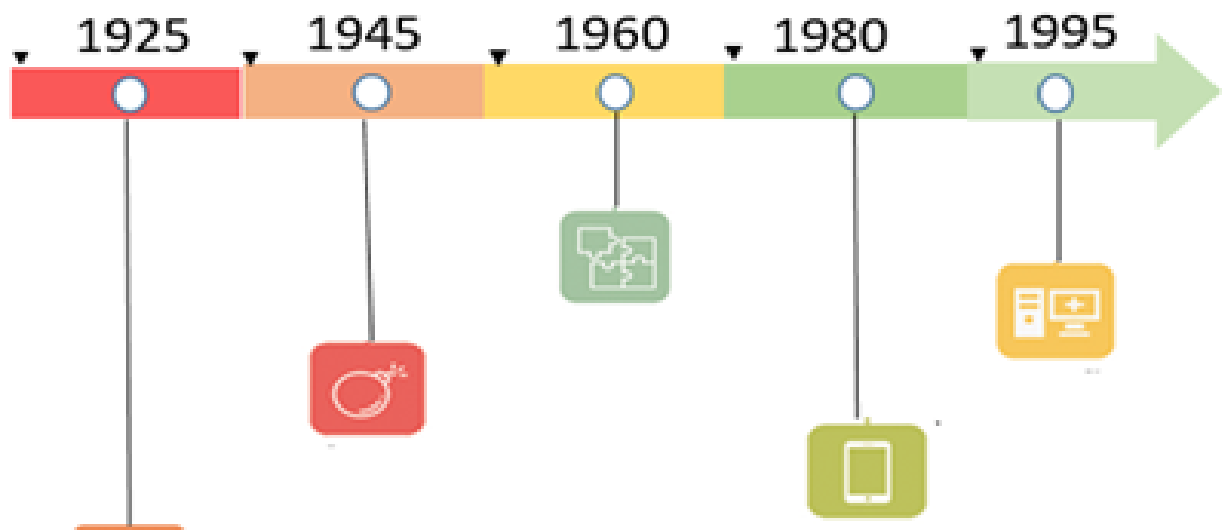

Figure 1 - Generation theory - each icon represents one of the described generations. In order, from left to right: Traditional, Baby Boomers, Generation X, Generation Y and Generation Z. Source: Authorial image. 


\section{Mentoring and digital medicine}

Digital medicine has been increasingly incorporated by health workers. As an example, Dr. Eric Topol, one of the most influential cardiologists in the world, developed a training matrix aiming at training English healthcare professionals. This tool showed that digital mindset was an important feature of the mentor for the development of young leaders. Extending to a post-COVID-19 pandemic world, these skills and mindset become relevant to patient care, since the pandemic has introduced an environment marked by electronic medical records, robotic tools, teleconsultation and telemonitoring. ${ }^{16,18,19}$

Under this new perspective, the development of digital medicine-related skills will enable the incorporation of a new health care model, different from the pre-pandemic setting. Therefore, there will be another chapter in the history of humanity, in which the outbreak of a certain disease alters the dynamics of health, functioning as a path for the humanistic development of professionals in the area. ${ }^{20}$

\section{Mentoring in Cardiology training}

The American Heart Association (AHA) and the American College of Cardiology (ACC) have used the mentoring process to train physicians, researchers, and cardiovascular scientists, aiming to accelerate the teaching and learning process of young professionals. The ACC pioneered the development of a structured mentoring process for cardiovascular professionals and scientists and edited an important publication: the "Mentoring Handbook", which is in the third publication ${ }^{20}$ This manual aims to promote the mentoring relationship between clinicians and senior researchers. Written for physicians and basic science researchers in a wide range of disciplines, this popular handbook is a practical guide to promote successful mentoring relationships between clinicians and senior and early-career scientists. In addition, it includes updated lists of mentoring resources and funding opportunities for young researchers. ${ }^{20}$

The Brazilian Society of Cardiology (SBC), in conjunction with the University of Duke, implemented in 2008-2009 an institutional program, to create a partnership in clinical research. ${ }^{5}$ The collaboration between the SBC and the Duke University resulted in increased productivity in

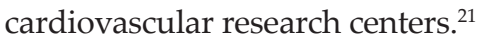

In 2018, during its $35^{\text {th }}$ conference, the SOCERJ started a mentoring project, which is in the third edition. Over the years, there has been substantial growth in demand for the program. The objective is to enable, during a oneyear partnership, that medical mentors and professors of excellence in the field of cardiology help medical academics and young doctors to manage their careers assertively, develop scientific initiation projects, guide on postgraduate programs, and develop personal skills. ${ }^{21}$

\section{SOCERJ 2019-2020 mentoring program experience}

The SOCERJ mentoring program had a great impact on the career of some participants in the first edition. Some of the mentees got into the master's degree program, managed to organize the curriculum to try residency in the United States, wrote and submitted the scientific papers and, mainly, got feedback on the skills that needed to be improved to achieve their goals. The opportunity to be in contact with successful doctors and teachers allowed mentees to raise improve their standard level of performance and become professionals of excellence.

The SOCERJ mentoring meetings take place according to the availability of the mentor and the demand of their projects. Face-to-face meetings are carried out weekly between academics and mentors for preparation of their first scientific papers. During the COVID-19 pandemic, these meetings were held online, keeping the same objectives, constancy, and deadlines.

A mentor's opinion in the context of new medical skills in the chronic cardiovascular diseases context

Advances in the diagnosis and treatment of cardiovascular diseases have allowed a marked increase in survival and quality of life of patients. In this new context, the doctor maintains a long-term routine follow-up of the patients. Diseases such as heart failure, atherosclerotic arterial disease, atrial fibrillation, systemic arterial hypertension and cardiometabolic conditions have become chronic diseases in an increasingly elderly population with multiple comorbidities and different levels of frailty.

The training of young doctors and cardiologists of the 20th century has followed a teaching model in which they should act in isolation, maintain a certain distance, deciding alone the direction of care and treatment of the patient. In recent decades, however, the multidisciplinary work and the formation of a cardiological team at care institutions have favored the complex health system, which increasingly requires professionals to develop teamwork skills, interdependence management, leadership attributes and active clinical governance. 
This new perspective will increasingly count on the support of different specialists such as family doctors, hospitalists, palliative care physicians, intensivists, rehabilitation professionals and multidisciplinary teams. Models of health care and clinical management have become fundamental in the competence matrix of the cardiologist of the 21st century, as well as the mastery of new areas such as telemedicine, nanomedicine and genetics/genomics as important tools for diagnosis and treatment.

Thus, a new relationship based on the doctor-patientfamily triad has been established, with a strengthening of the bonds of trust and shared decision-making. Also, a space is opened for patients to become participative in treatment choices and procedures, and to assume their self-care. In this way, choices are aligned with their preferences, values, and beliefs.

In this dynamics, heart disease patient becomes an active individual in the acquisition of information about his/her disease and is no longer satisfied with consuming prescriptions and guidelines. The physician is a professional who can adapt the therapeutic approaches and respects patient complexity as a biopsychosocial spiritual being. ${ }^{22}$

\section{Conclusion}

The mentoring process in cardiology begins to be developed as a tool of broad and fundamental use in the formation of human capital. Young and senior cardiologists will face a growing challenge throughout their professional life, working in an environment of uncertainty, regulatory, health and epidemiological

\section{References}

1. SILVA, CRE. Revista Brasileira Orientação Profissional [Internet]. Porto Alegre: Associação Brasileira de Orientação Profissional; 2010 [cited 2020 Abr 20] Available from: http://pepsic.bvsalud.org/scielo.php?script=sci_ abstract\&pid=S167933902010000200014\&lng=es\&nrm=is\&tlng=pt.

2. Botti SHO, Rego S. Preceptor. Supervisor, Tutor e Mentor: Quais São Seus Papéis? Rev Bras Educ Med. 2008;32(3):363-73. doi: 10.1590/S010055022008000300011.

3. Moreira SNT, Albuquerque ICS, Gomes AHB, Pinto FEL Jr. Programa de Mentoria do Curso de Medicina da Universidade Federal do Rio Grande do Norte: Atividades Integrativas em Foco. Rev. bras. educ. med. 2020;44(4):169. doi:10.1590/1981-5271v44.4-20200103.

4. Olá Sejam Bem-Vindos à Mentoria FMUSP [Internet]. São Paulo: Faculdade de Medicina da Universidade de São Paulo [cited 2021 Mar 07] Available: https://www.fm.usp.br/mentoria/portal/.

5. Barros NF, Lourenço LCA. O Ensino da Saúde Coletiva no Método de Aprendizagem Baseado em Problemas: Uma Experiência da Faculdade changes, and mainly with the new format of well informed and participatory patients with regard to their care. Therefore, multiple mentoring model and digital mindset are imperative in the training process and should be led by educational organizations and cardiology societies.

\section{Acknowledgements}

We dedicate this text to three special mentors: Raul Carlos Pareto Junior, Stans Murad Neto and Charles Mady.

\section{Author contributions}

Conception and design of the research: Mesquita ET. Acquisition of data: Soares AC, Matos RC. Analysis and interpretation of the data: Mesquita ET. Writing of the manuscript: Soares AC. Critical revision of the manuscript for intellectual content: Soares AC, Mesquita ET, Matos RC.

\section{Potential Conflict of Interest}

No potential conflict of interest relevant to this article was reported.

\section{Sources of Funding}

There were no external funding sources for this study.

\section{Study Association}

This study is not associated with any thesis or dissertation work. de Medicina de Marília. Rev Bras Educ Med. 1997;30(3):136-46. doi: 10.1590/S0100-55022006000300004.

6. McNamara MS, Fealy GM, Casey M, O'Connor T, Patton D, Doyle L, et al. Mentoring, Coaching and Action Learning: Interventions in a National Clinical Leadership Development Programme. J Clin Nurs. 2014;23(1718):2533-41. doi: 10.1111/jocn.12461.

7. Agarwal S. Mentorship during Fellowship. J Am Coll Cardiol 2014;64(15):1637-8. doi: 10.1016/j.jacc.2014.08.017.

8. Premkumar K, Pahwa P, Banerjee A, Baptiste K, Bhatt H, Lim HJ Does Medical Training Promote or Deter Self-Directed Learning? A Longitudinal Mixed-Methods Study. Acad Med. 2013;88(11):1754-64. doi: 10.1097/ACM.0b013e3182a9262d.

9. Diretrizes Curriculares Nacionais do Curso de Graduação em Medicina n. 116 (April 03, 2014) [Internet]. Brasília: Ministério da Saúde; 2014 [cited 2021 Jul 07]. Available from: https://abmes.org.br/legislacoes/ detalhe/1618/parecer-cne-ces-n-116. 
10. Frellick M. Burnout Rises Above 50\% in Some Specialties, New Survey Shows. Medscape Medical News. 2019 Jan 17.

11. Janasz SC, Sullivan S, Whiting V. Mentor Networks and Career Success: Lessons for Turbulent Times. Acad Manag Perspect. 2003;17(4). doi: 10.5465/AME.2003.11851850.

12. Kram K. Phases of Mentor Relationship. Academy of Management Journal. 1983;26(4):608-65. doi:10.2307/255910.

13. Straus W, Howe N. The Cycle of Generations. American Demographics. 13rd ed. New York: William Morrow \& Co; 1991.

14. Gerações Y e Z: Juventude Digital. Instituto Brasileiro de Opinião Pública e Estatística [Internet]. Rio de Janeiro: IBOPE; 2010 [cited 2021 Jul 07]. Available from: http://www4.ibope.com.br/download/geracoes $\% 20$ _y_e_z_divulgacao.

15. Teixeira APP, Gamarra LT, Kuhsler C, Petuco CF, Teixeira R, Klein AZ. O Sentido do Trabalho: Uma Análise à Luz das Gerações Xe Y. Diálogo. 2014;(25):25-37.

16. Prensky M. Nativos Digitais Imigrantes Digitais. De On the Horizon NCB University Press. 2001;9(5):1-6.
17. Watté BH, MarcioS. A efetividade do e-mentoring no Desenvolvimento de Competências de Liderança. Congresso Internacional de Conhecimento e Inovação 2019; 2019 Nov 07-08; Porto Alegre, BR. 2019.

18. Topol EJ, Verghese A. Medicine End the Machine. Medscape Medical News. 2020 Jan 02

19. Magalhães S, Machado C. Conceitos epidemiológicos e as pandemias recentes: novos desafios. Cad. Saúde Colet.2014;22(1):109-10. doi:10.1590/1414$462 \times 201400010016$.

20. American Heart Association. The AHA Mentoring Handbook. 2nd ed. Philadelphia: Lippincott Williams \& Wilkins; 2012.

21. Pellanda LC, Cesa CC, Belli KC, David VF, Rodrigues CG, Vissoci JRN, et al. Research training program: Duke University and Brazilian Society of Cardiology. Arq Bras Cardiol. 2012;99(6):1075-81. doi: 10.1590/S0066$782 \mathrm{X} 2012001500002$.

22. Dal-FarraI R, GeremiaI C. Educação em Saúde e Espiritualidade: Proposições Metodológicas. Rev Bras Educ Med. 2010;34(4): 587-97. doi: 10.1590/S010055022010000400015 . 